\title{
Low-level buoyancy as a tool to understand boundary layer transitions
}

\author{
Francesca M. Lappin ${ }^{1,2}$, Tyler M. Bell ${ }^{1,2,3,5}$, Elizabeth A. Pillar-Little ${ }^{1,2}$, and Phillip B. Chilson ${ }^{1,2,4}$ \\ ${ }^{1}$ School of Meteorology, University of Oklahoma, Norman, OK, USA \\ ${ }^{2}$ Center for Autonomous Sensing and Sampling, Norman, OK, USA \\ ${ }^{3}$ Cooperative Institute for Mesoscale Meteorology, Norman, OK, USA \\ ${ }^{4}$ University of Oklahoma Advanced Radar Research Center, Norman, OK, USA \\ ${ }^{5}$ NOAA/OAR National Severe Storms Laboratory, Norman, OK, USA
}

Correspondence: Francesca Lappin (francesca.lappin@ou.edu)

\begin{abstract}
Advancements in remotely piloted aircraft systems (RPAS) introduced a new way to observe the atmospheric boundary layer $(\mathrm{ABL})$. Adequate sampling of the lower atmosphere is key to improving numerical weather models and understanding fine-scale processes. The ABL's sensitivity to changes in surface fluxes leads to rapid changes in thermodynamic variables. This study proposes using low-level buoyancy to characterize ABL transitions. Previously, buoyancy has been used as a bulk parameter to quantify stability. Higher resolution data from RPAS highlight buoyancy fluctuations. RPAS profiles from two field campaigns are used to assess the evolution of buoyancy under convective and stable boundary layers. Data from these campaigns included challenging events to forecast accurately, such as convective initiation and a low-level jet. Throughout the daily ABL transition, results show that the ABL height determined by the minimum in vertical buoyancy gradient agrees well with proven ABL height metrics, such as potential temperature gradient maxima. Moreover, in the cases presented, low-level buoyancy rapidly increases prior to convective initiation and rapidly decreases prior to the onset of a low-level jet. Low-level buoyancy is a function sensitive in space and time, and with further analysis could be used as a forecasting tool. This study expounds on the utility of buoyancy in the ABL and offers potential uses for future research.
\end{abstract}

\section{Introduction}

The atmospheric boundary layer (ABL) is strongly influenced by kinematic and thermodynamic interactions with the Earth's surface. It is sensitive to changes in radiation, low-level moisture, and heat fluxes. The ABL functions as a conduit for moisture and warm air to be transported vertically. As a consequence, the depth of the ABL (referred to herein as ABL height) and the ABL stability fluctuate in time and space (Lenschow et al., 1979; Stull, 1988). This influences local weather (Lapworth, 2006), turbulence (Banta et al., 2003; Bonin et al., 2013), and aerosol transport (Nilsson et al., 2001; De Wekker et al., 2009; Pal et al., 2014). The nature of the ABL makes it both crucial to successful numerical weather prediction (NWP) yet incredibly difficult to represent. Most boundary layer parameterizations are based off of decades old observation methods. Often, the best choice for boundary layer parameterizations is situationally dependent to what is being modeled (Braun and Tao, 2000; Nolan et al., 2009; Hu et al., 2010; Cuchiara et al., 2014; Cohen et al., 2015). Weather and climate models will continue to struggle 
to accurately represent the ABL without vertical, high-resolution observations (Steeneveld et al., 2008; Teixeira et al., 2008; Baklanov et al., 2011). Assimilating in situ data has been shown to benefit the performance of the model (Ruggiero et al., 1996; Otkin et al., 2011; Jonassen et al., 2012; Ágústsson et al., 2014; Reen et al., 2014; Jones et al., 2016; Degelia et al., 2018). The lack of accessible technology to accurately sample the ABL has slowed advancements throughout the field. Up until recently, this type of data have not been easily retrievable.

In the past, it has proven difficult to collect adequate spatially and temporally resolved measurements within the ABL, resulting in a "data gap". Since the National Research Council (2009) called for more vertical measurements in the ABL, there have been technological advancements to address the gap. Remote sensors such as microwave radiometers, lidars, and scatterometers can continuously measure the lower atmosphere, which have been shown to improve short-term forecasts (Jones and Stensrud, 2012; Coniglio et al., 2019; Hu et al., 2019; Lewis et al., 2020). However, these instruments are expensive and relatively immobile, which limits the environments they can sample. For example, pre-convective environments change rapidly, and instruments need to relocate quickly to gain targeted observations. Radiosondes are used across the United States for taking upper air measurements, typically twice daily. Unfortunately, radiosondes are only released frequently enough to capture mesoscale changes during field experiments. Of equal importance, they travel too quickly through the ABL for thorough characterization.

Increasing interest in remotely piloted aircraft systems (RPAS) across many sectors has accelerated improvements in quality and availability of RPAS technology (Reuder et al., 2009; Elston et al., 2015; Villa et al., 2016). In turn, the capabilities of RPAS broadened and its usefulness in research became obvious. The benefits of utilizing RPAS in atmospheric sciences have been proven across many situations, including turbulence observations and data assimilation (Dias et al., 2012; Båserud et al., 2016; Flagg et al., 2018; Barbieri et al., 2019). RPASs can be readily reused to sample rapidly changing environments, and can be paired with remote sensors to describe the lower troposphere more completely. In Bell et al. (2020a) measurements from RPAS, radiosondes, and remote sensors were found to agree well with each other. The study also discusses functionality of each platform. While RPASs allow for more adaptive sampling, there are more federal regulations and air restrictions governing their use. Nonetheless, some specially designed RPASs can deliver equally accurate measurements as radiosondes with a higher spatial resolution and are more cost-efficient.

Diurnal cycles in temperature and humidity characterize ABL transitions, driving changes in ABL height and stability. There are numerous ways to determine the ABL height, many of which are described and tested in Dai et al. (2014) and Dang et al. (2019). Notably, potential temperature proved to be a highly accurate method of estimating ABL height with vertical data resolution less than $20 \mathrm{~m}$ (Dai et al., 2014). Similarly, sharp gradients in humidity have been used to determine the ABL height for both stable and convective boundary layers when using lidar data (Hennemuth and Lammert, 2006). Dang et al. (2019) also evaluated different systems to determine ABL height, which did not include RPAS, and determined lidar-based profiles would benefit NWP. A common thread throughout these studies is that there is no perfect determination for ABL height, nor is there a perfect platform (Seibert et al., 2000; Dai et al., 2014; Dang et al., 2019). While there will always be benefits and drawbacks to observation platforms, it is possible that RPAS could marry some of the pros, while reducing costs. Alongside the evolution of sampling strategies, there follows new ways to determine the ABL height. 
Buoyancy is a fundamental principle in fluids caused by density or temperature differences that quantifies stability. Buoyant parcels rise from the warm surface and convectively mix the ABL. This process is the foundation behind most gradient-based ABL height methods previously mentioned. Additionally, it has been used in attempts to forecast severe weather. Buoyancy is the basis for convective parameters like convective available potential energy (CAPE) and convective inhibition (CIN). CAPE is buoyancy integrated between the level of free convection and the equilibrium level, which may not always exist in every environment. Since CAPE is a bulk parameter, the most substantial influence comes at mid-levels. Climatologically, CAPE has correlated directly with storm intensity (Zhang and Klein, 2010) but has little short-term prognostic value (Ziegler and Rasmussen, 1998). CAPE and CIN lack the small scale, near-surface effects needed to understand convective initiation (CI). As a result, mean radiosonde derived values of CAPE and CIN do not significantly differ between deep convection and fair weather days (Zhang and Klein, 2010). Yet, in the same study, average low-level $(<5 \mathrm{~km})$ buoyancy does significantly differ. Moreover, single-level, simulated buoyancy values rapidly intensify, overcoming entrainment dilution prior to CI (Houston and Niyogi, 2007; Trier et al., 2014). Additionally, buoyancy is used to quantify cold pool strength. Simulations indicate that an ample cold pool is key to long-lasting quasi-linear convective systems (Weisman and Rotunno, 2004). Another facet of buoyancy is its influence on modeled low-level jet (LLJ) speed. The strength of positive buoyancy had a direct relation with the maximum wind speed for southerly LLJs (Shapiro and Fedorovich, 2009; Shapiro et al., 2016). Conversely, large positive buoyancy impedes the initiation of northerly LLJs, such that negative buoyancy is beneficial to the northerly LLJs (Gebauer et al., 2017). Proper understanding of LLJs has implications on deep convection, air quality, and wind energy.

In short, the utilities of buoyancy have been shown by models but few studies have yet to substantiate them with in situ observations. Recent developments in RPASs allow us to gather the necessary measurements to test these hypotheses in real environments. Furthermore, it opens the door for improving NWP with data assimilation. This paper will look at how low-level buoyancy evolves with time over multiple settings. Data from RPASs and radiosondes will help us evaluate low-level buoyancy as a tool to understand ABL transitions for a CI and LLJ case.

\section{Campaigns}

Here we consider examples of data collected using RPAS and radiosondes during two different field campaigns. Both campaigns aimed to display the usefulness of RPAS under various atmospheric phenomena. Flux-Capacitor sampled boundary layer transitions under a common southern plains occurrence, the LLJ. The Lower Atmospheric Process Studies at Elevation-a Remotely Piloted Aircraft Team Experiment (LAPSE-RATE) campaign was uniquely located at high-altitude with orographically driven circulations and different land surfaces. We will use these data to evaluate the utility of low-level buoyancy in various environments. All flights completed during both campaigns were conducted under Federal Aviation Administration (FAA) certificates of authorization (COA) and overseen by FAA licensed pilots, who were embedded with the research teams. A complete description for each campaign follows. 


\subsection{Flux-Capacitor}

The Flux-Capacitor field campaign took place as a test of the 3D Mesonet concept in which a subset of Oklahoma Mesonet stations would include a RPAS capable of regularly profiling the lower troposphere (Chilson et al., 2019). Starting 05 October 2018, 24 hours of flights were completed at 30 min intervals. This campaign sampled the ABL throughout its diurnal cycle and under southerly LLJ conditions. The flight ceiling for Flux-Capacitor was based on line of sight operations up to 1,200 $\mathrm{m}$. Flights took place $28 \mathrm{~km}$ southwest of Norman, OK, USA at the Kessler Atmospheric and Ecological Field Station (KAEFS), which is co-located with the Oklahoma Mesonet's Washington station (WASH). Additionally, a radiosonde was released approximately every 3 hours, for a total of 10 soundings. Radiosondes served as a way to validate measurements from RPAS profiles.

\subsection{LAPSE-RATE}

LAPSE-RATE took place in San Luis Valley from 14-19 July 2018 (de Boer et al., 2020). Ten teams gathered to collect atmospheric measurements using RPASs for three targeted missions: CI, drainage flows, and boundary layer transition. Teams distributed across the valley regularly collected synchronized, vertical profiles of the atmospheric state up to $914 \mathrm{~m}$ above ground level with rotary-wing RPAS. Additional data were collected using fixed-wing RPAS, radiosondes, and ground-based remote sensors. Although there were many other RPASs and remote sensing platforms used, we will focus on the two CASS deployed stations. This allows for direct comparisons with the Flux-Capacitor campaign as the same RPAS was used. CASS had two profiling stations, one at Moffat School (MOFF) and the other approximately $27 \mathrm{~km}$ northwest at Saguache Airport (K04V). During ABL transitions, flights were completed at 15 min intervals. Otherwise, flight frequency was $30 \mathrm{~min}$.

This campaign was unique in location and execution. The San Luis Valley has an average elevation of 2,300 $\mathrm{m}$ and peaks at 4,000 $\mathrm{m}$ above sea level. The valley is arid but contains irrigated cropland creating gradients in temperature and moisture from differing land uses. There is orographic lift, which leads to convection commonly occurring overtop the mountains. Furthermore, mountain-valley circulations affect ABL transitions and air quality. Teams were able to partially sample the valley, which is nearly the size of Connecticut, by completing over 1,200 flights, using 34 different platforms (Boer et al., 2020; Pillar-Little et al., 2020).

\section{Observation platforms}

During the LAPSE-RATE campaign, there were numerous RPASs collecting data in addition to remote sensing platforms and ground station observers. All data obtained during LAPSE-RATE can be found at https://zenodo.org/communities/lapse-rate/. Flux-Capacitor utilized the CopterSonde, radiosondes, and surface observations. In order to have direct comparisons between the two datasets, we chose to only use the data from radiosondes and the CopterSonde. The description of these two platforms follows. 


\subsection{CopterSonde}

The RPAS utilized in both field campaigns was the CopterSonde 2. This is a rotary wing quadcopter designed and manufactured by Center for Autonomous Sensing and Sampling (CASS) at the University of Oklahoma. The CopterSonde contains three temperature sensors (iMet-XF glass bead thermistors) and three relative humidity sensors (Innovative Sensor Technology HYT 271). These are placed within the shell of the aircraft, protecting them from solar radiation and heat from the motor, which can impact the precision of the measurements (Greene et al., 2018, 2019). Pressure is determined by the MS561 pressure sensor within the autopilot. Built into the shell is an aspirated intake scoop that is designed to consistently draw air across the sensors. It features a sampling technique that adapts to position the intake scoop into the wind. Consequently, this improves measurement accuracy and eliminates the need for additional wind speed and direction sensors (Segales et al., 2020; Greene et al., 2019). The sensor scoop was tested in the Oklahoma Climatological Survey calibration laboratory. The bias for each sensor is calculated and applied to the CopterSonde data. These adjustments are built off of trials from previous campaigns such as Environmental Profiling and Initiation of Convection (EPIC; Koch et al. (2018) and 2018 Innovative Strategies for Observations in the Arctic Atmospheric Boundary Layer (ISOBAR; Kral et al. (2018)). The CopterSonde is continually improving its wind speed and direction algorithm.

\begin{tabular}{|c|c|c|c|c|c|}
\hline Date & Time (UTC) & Number of flights & Avg. flight frequency (min) & Location & Mission \\
\hline 20180715 & $1326-1944$ & 18 & 15 & MOFF & CI \\
20180715 & $1400-1915$ & 12 & 30 & K04V & CI \\
20180719 & $1150-1700$ & 24 & 15 & MOFF & Drainage flow \\
20180719 & $1130-1700$ & 22 & 30 & K04V & Drainage flow \\
20181005 & $1500-2335$ & 18 & 30 & KAEFS & LLJ \\
20181006 & $0000-1431$ & 28 & 30 & KAEFS & LLJ \\
\hline
\end{tabular}

Table 1. Summary of CopterSonde flights from Flux-Capacitor and LAPSE-RATE.

CopterSonde and radiosonde data gathered in these campaigns were compared in Bell et al. (2020a), in addition to data from the Collaborative Lower-Atmospheric Mobile Profiling System (CLAMPS) (Wagner et al., 2019). Temperature, humidity, wind speed and direction from each system were compared and showed strong agreement.

\subsection{Radiosonde}

Radiosondes have stood as the standard for atmospheric measurements for over 90 years and have served as a validation tool for many novel sensing platforms. The Vaisala RS92-SGP radiosonde was used for this study. Data from the radiosondes are initiated from ground station data. According to Vaisala technical data, there is a $0.5{ }^{\circ} \mathrm{C}$ uncertainty for temperature and $5 \%$ uncertainty for relative humidity. The measurement response time for both sensors is less than $0.5 \mathrm{~s}$. Further information regarding the radiosondes used during LAPSE-RATE can be found in Bell et al. (2020b). 


\section{Methods}

The CopterSonde allowed for controlled measurements taken at a prescribed frequency specified by the needs of each campaign. Table 1 describes flight strategies in both experiments. Abiding by FAA air regulations, the flight ceiling for FluxCapacitor was 1,524 m (5,000 ft) above ground level (AGL) with line of sight operations required. Lights affixed to the RPAS allowed visibility into the night, but due to high winds, a majority of Flux-Capacitor flights did not reach the flight ceiling. As for LAPSE-RATE, flights were authorized up to $914 \mathrm{~m}$ (3,000 ft) AGL, which most flights reached.

Buoyancy $(\beta)$ was calculated at each level using Eq. (1) such that the vertical resolution is the same as all other variables. The parcel temperature $\left(T_{\text {par }}\right)$ was calculated based on parcel theory with the lowest observed temperature and dew point used as the initial inputs. The temperature measured by the RPAS or radiosonde functions as the environmental temperature $\left(T_{\text {env }}\right)$ while $\mathrm{g}$ is the acceleration due to gravity.

$$
\beta=g * \frac{T_{p a r}-T_{e n v}}{T_{e n v}}
$$

CopterSonde data were recorded at $10 \mathrm{~Hz}$ and then downsampled to a $3 \mathrm{~m}$ vertical resolution for Flux-Capacitor and $10 \mathrm{~m}$ for LAPSE-RATE. As for the radiosondes, the data were vertically interpolated to mimic the sampling resolution of the CopterSonde. Example profiles $T_{p a r}, T_{e n v}$, and $\beta$ using CopterSonde data are provided in Fig. 1 . The detailed account of how the LAPSE-RATE data were processed can be found in Pillar-Little et al. (2020). The integrated buoyancy for the radiosondes was calculated up to the flight ceiling for the CopterSonde closest to release time. Since flight ceilings change based on flying conditions, this was done to make the results most comparable.

Two methods were used to determine the ABL height during Flux-Capacitor. The control method finds the height of maximum vertical potential temperature gradient, hereafter called potential temperature method. It was chosen because it has shown to be applicable in stable and convective boundary layers over land (Martucci et al., 2007). The hypothesized method finds the height of the minimum buoyancy gradient, hereafter called buoyancy method. Above the ABL, the atmosphere becomes more stable; therefore, the height of the ABL should be found where the uniformly mixed buoyancy begins to decrease sharply. To smooth over some individual spikes in the CopterSonde data, a 5-point $(15 \mathrm{~m})$ running mean was applied across the entire profile to derived quantities including, potential temperature, dew point temperature, mixing ratio, and buoyancy. The calculations to attain these values may have introduced noise. This was not necessary for the radiosonde data since it was processed by Vaisala software then additionally vertically interpolated.

\section{Results}

\subsection{Case 1: Flux-Capacitor}

Radiosondes and the CopterSonde were regularly deployed allowing them to be cross evaluated. Both platforms share similarities in quantities and dimension sampled. Nonetheless, there are stark differences in abilities. Radiosondes are capable of sampling a much higher column, while the CopterSonde's flight ceiling is limited greatly by regulation, technology, and 

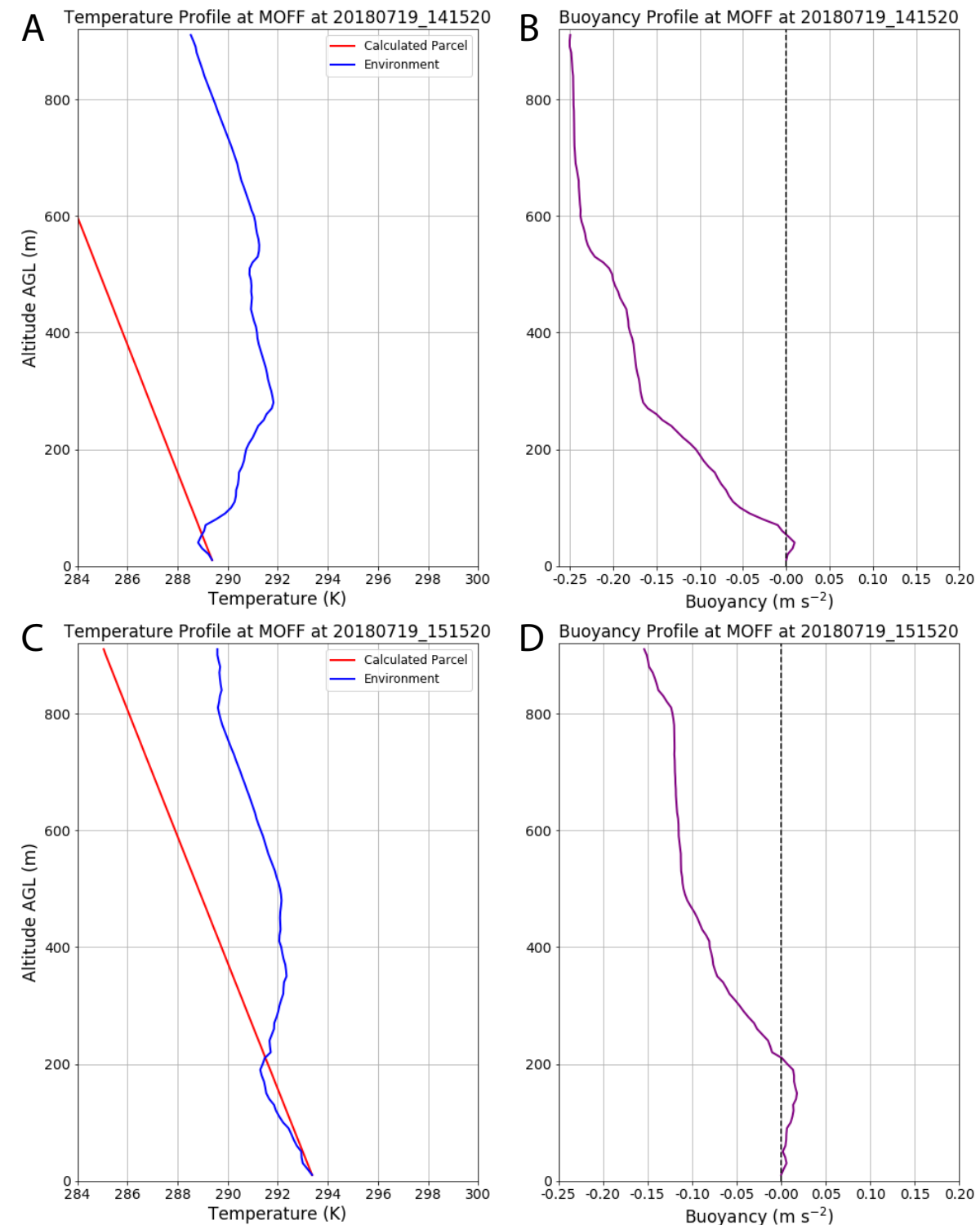

Figure 1. Temperature (K) and buoyancy $\left(\mathrm{m} \mathrm{s}^{-2}\right.$ ) profiles from CopterSonde at MOFF on 19 July 2018. (a,c) Temperature observed from CopterSonde (red) and dry adiabatically lifted parcel (blue). (b,d) Buoyancy profile (purple) black dashed line at neutral (zero) buoyancy.

atmospheric conditions. Radiosondes are Lagrangian tracers; they are advected with the flow and therefore represent locations downwind of the release site. The CopterSonde conducts fixed location profiles delivering true local vertical gradients. Moreover, the cost of a radiosonde profile is much greater than a CopterSonde profile, restricting the temporal resolution of radiosondes. Nevertheless, the long established confidence in radiosondes makes them a validation tool for measurements from the CopterSonde. Figure 2 shows the temperature at the lowest measured elevation from both platforms in addition to the Ok- 


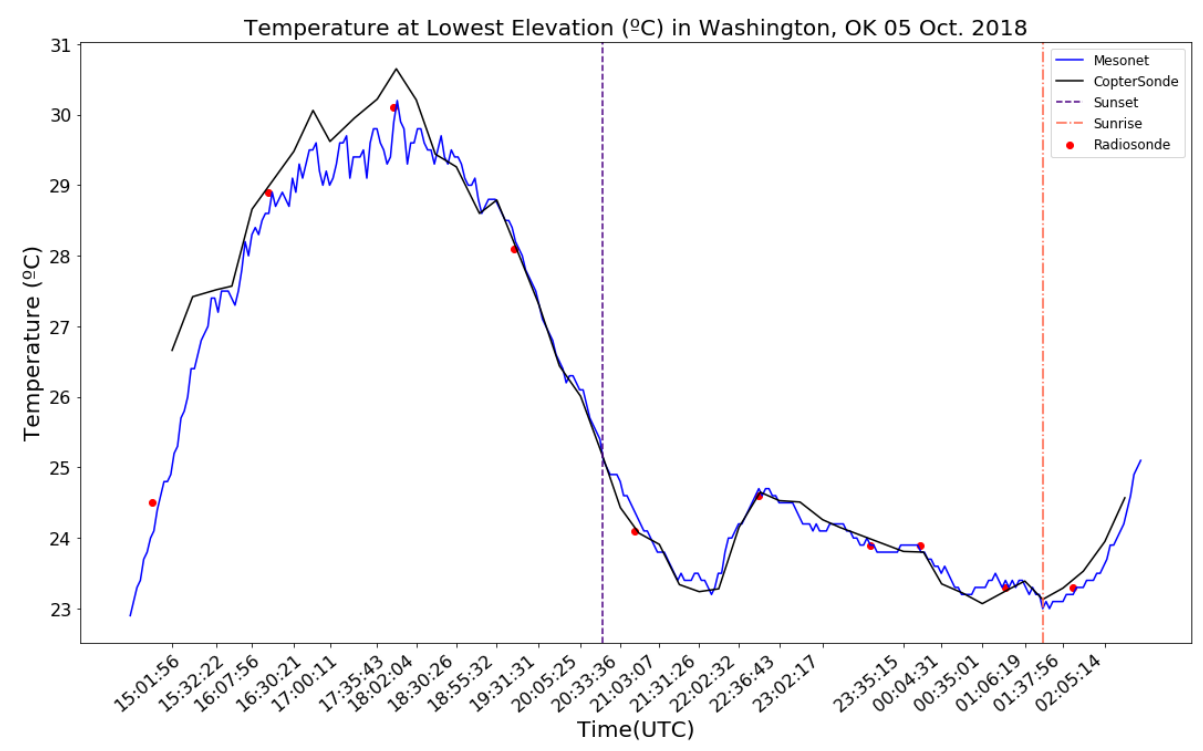

Figure 2. Time series of temperature $\left({ }^{\circ} \mathrm{C}\right)$ measured at the lowest level from the Mesonet $(9 \mathrm{~m})$ (blue line), CopterSonde (6 m) (black line), and radiosondes $(7 \mathrm{~m}$ ) (red dot) from 1500 UTC 05 October 2018 - 1430 UTC 06 October 2018.Purple and orange vertical lines represent sunset and sunrise, respectively.

lahoma Mesonet's $9 \mathrm{~m}$ temperature observation. The radiosondes used in this field campaign take in the station measurements as a boundary condition, which explains strong agreement between radiosondes and Mesonet data. Initially, the CopterSonde has approximately a $1{ }^{\circ} \mathrm{C}$ warm bias at the lowest elevation. This is a consequence of the shell being heated by the sun before takeoff. Continuous aspiration over the sensors above the surface would reduce this effect at higher elevations. New protocols have been initiated to mitigate this effect. Moreover, the warm bias reduces to near-zero at 2103 UTC. Therefore, there is confidence in the accuracy of temperature measurements, thus the initialization point for buoyancy profiles. 


\section{A}

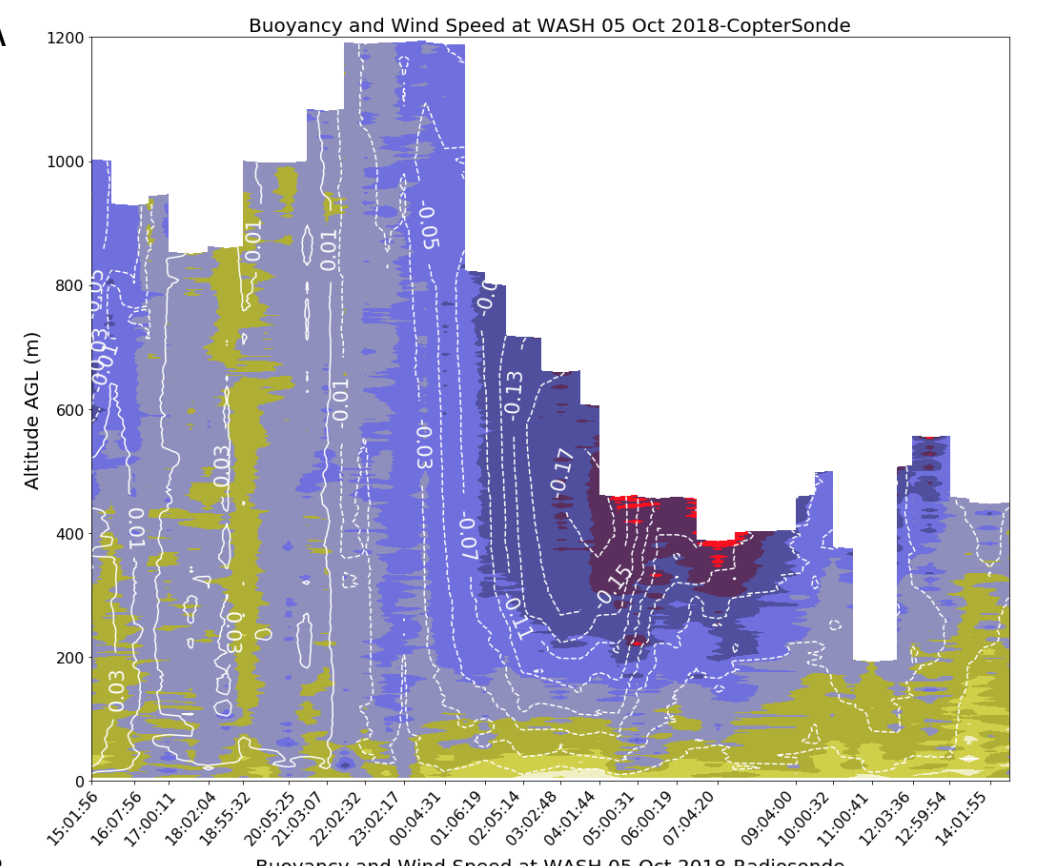

B

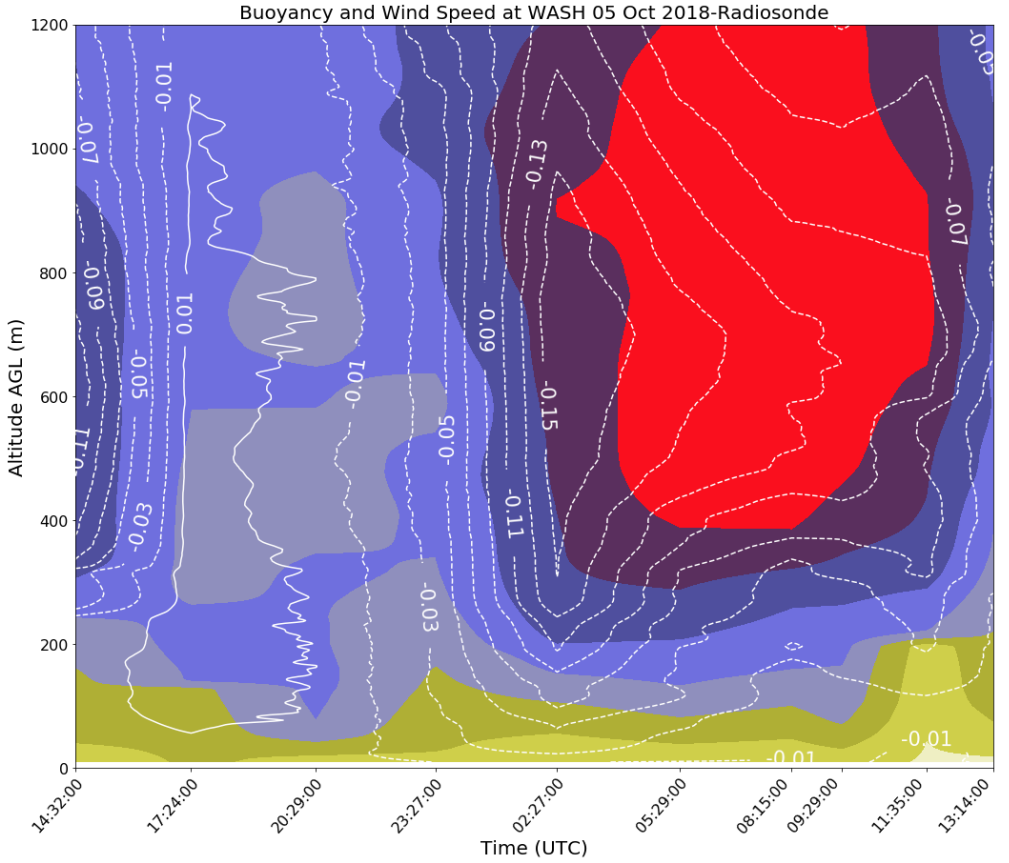

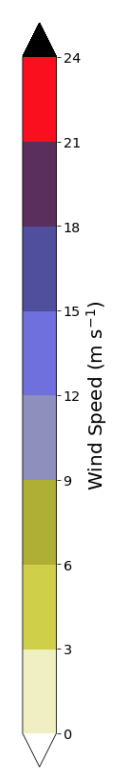

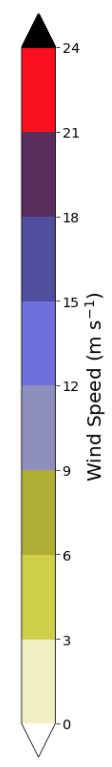

Figure 3. Buoyancy contours $\left(\mathrm{m} \mathrm{s}^{-2}\right)$ where solid(dashed) are positive(negative) and wind speed $\left(\mathrm{m} \mathrm{s}^{-1}\right)$ filled contours on 05-06 October 2018 in Washington, OK. (a) plotted data comes from 46 CopterSonde flights (b) plotted data comes from 10 radiosondes. Every other flight is represented by the times on the $\mathrm{x}$-axis. 


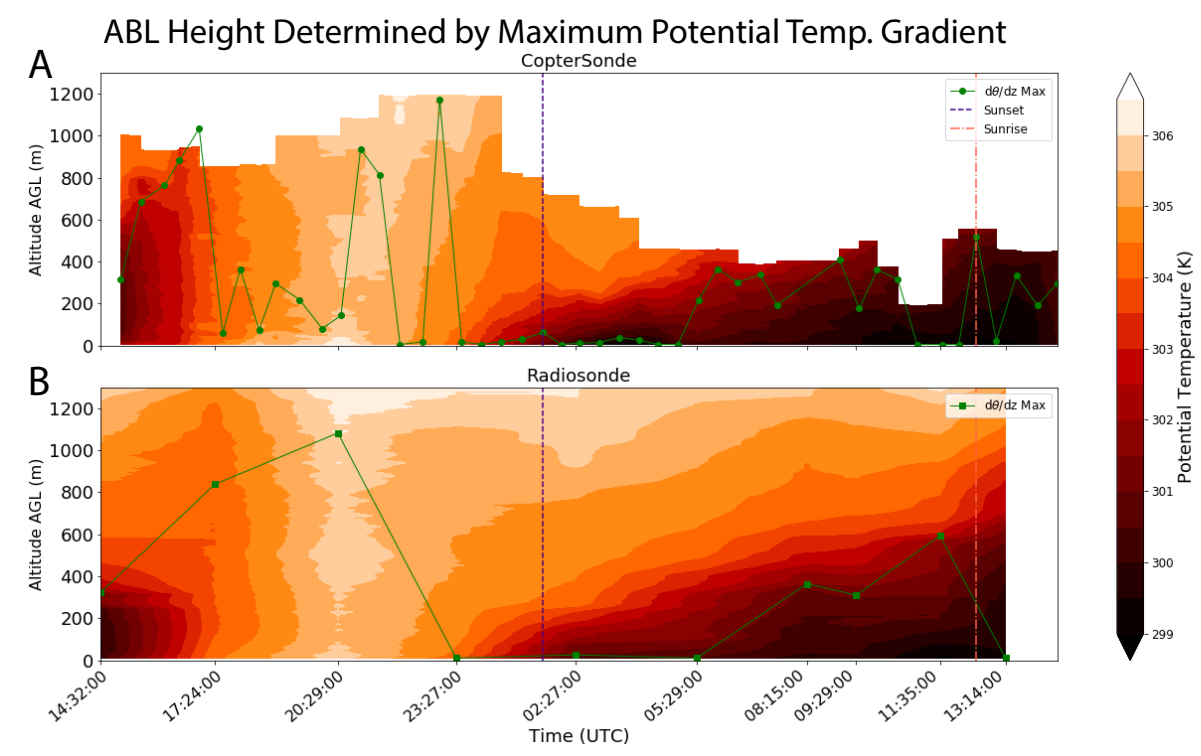

Figure 4. Potential temperature field (shaded contours) and green line indicating the ABL height determined by height of maximum potential temperature gradient. a) each circle indicates the height determined by an individual flight. b) each square indicates the height determined by an individual radiosonde.

Figure 3 shows the contours of calculated buoyancy in time and height from the CopterSonde (a) and the radiosondes (b) over shaded wind speed. Profiles from each platform are interpolated over time and height to create the continuous figures. The atmosphere's turbulent nature is highlighted by fine-scale changes in the wind speed shown by the increased vertical data resolution with the CopterSonde coupled with the increased frequency of profiles (more flights). The change in flight ceilings seen in Fig. 3a shows the limitations of flying in a high wind environment. Nonetheless, the change in buoyancy throughout the time period is similar for both platforms. This is particularly of interest from 0130 - 0430 UTC when a negative buoyancy gradient in time forms preceding the onset of the LLJ. The negative buoyancy is at its maximum about an hour prior to the wind speed maximum. This could be attributable to the downwelling of air before the LLJ. Figure 2 shows a local maximum in temperature at the time of maximum wind speed from $400-1,200 \mathrm{~m}$. As the warmer air aloft is mixed down, there is a slight rise in buoyancy around 0530 UTC (Fig. 3). All in all, this demonstrates that buoyancy is sensitive to changes in the lower troposphere.

After the initial analysis seen in Fig. 3, we find that buoyancy becomes convectively well-mixed throughout the daylight hours, as does water vapor and potential temperature. This is expected since buoyancy is a driving force to homogenize the ABL. Therefore, we propose a gradient-based method to find the ABL height from buoyancy profiles. In order to evaluate a new method, the ABL heights determined from the potential temperature method are also found (Martucci et al., 2007). The potential temperature method, radiosonde derived heights (Fig. 4b) do not change as rapidly as potential temperature method, CopterSonde derived heights (Fig. 4a). Moreover, the potential temperature method ABL heights from the CopterSonde data 


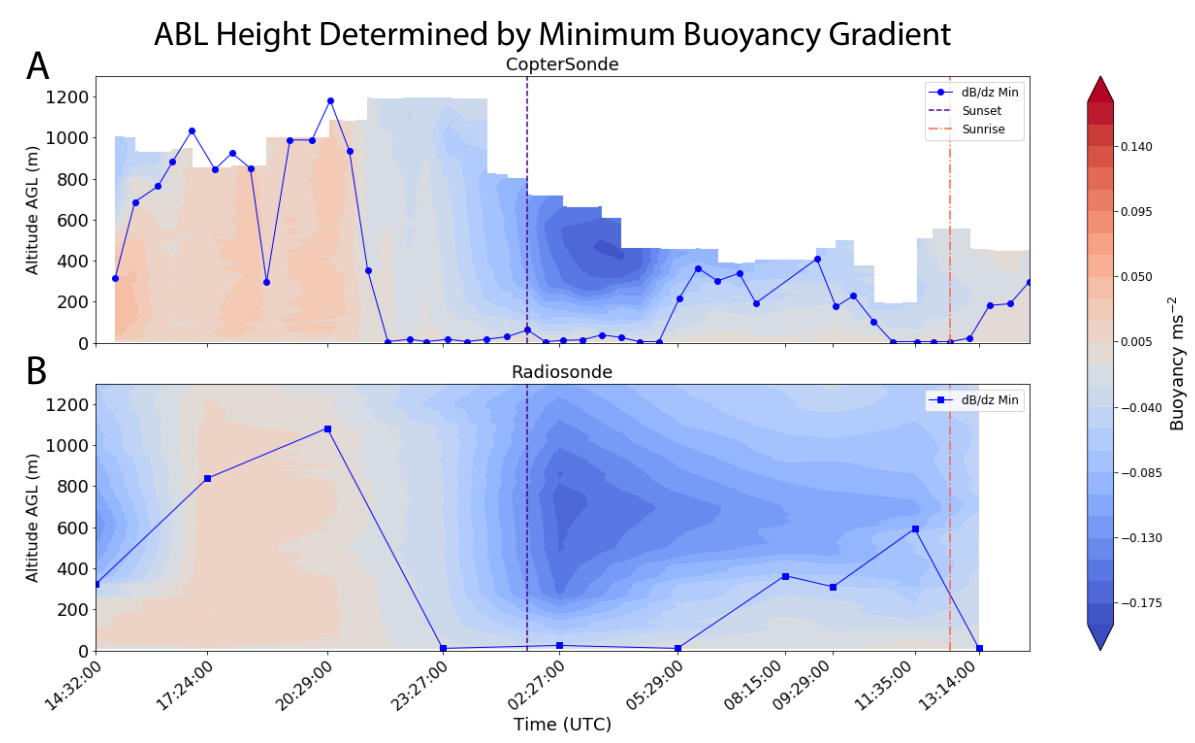

Figure 5. Same as Fig. 4 but with buoyancy field and buoyancy determined ABL heights (blue line).

are lower from 1724-2300 UTC compared to radiosonde derived heights. The dropoff in ABL height occurs once the mixed layer extends past the flight ceiling. Without a strong transition above the ABL, the potential temperature method erroneously finds where the surface layer transitions to the mixed layer. The CopterSonde is more likely to find these sharp gradients near the surface because of the increased data resolution at lower levels. Considering most ABL height methods are tested using radiosonde data, it is expected that the potential temperature method works well. Contrarily, the heights derived from the CopterSonde are deterred by the flight ceiling, which leads to a low bias in ABL depth.

It is worth pointing out the differences in sampled potential temperature. Around 1432-1500 UTC the height of mixed potential temperature disagrees strongly between the two sampling platforms (Fig. 4). The height of the mixed layer determined by a radiosonde release is around $330 \mathrm{~m}$ (Fig. 4b), while it is around $550 \mathrm{~m}$ for the CopterSonde (Fig. 4a). This pattern continues into the 1724 UTC radiosonde release. A measurement bias is not suspected, it is likely due to the radiosonde being advected downwind. Figure $3 \mathrm{~b}$ shows $15-18 \mathrm{~m} \mathrm{~s}^{-1}$ winds in the 350-970 m layer. Between the 1430 UTC radiosonde release and the first CopterSonde flight at 1501 UTC, the radiosonde would likely be many kilometers downstream of KAEFS. The difference in mixing layer depths can also be seen in the buoyancy data (Fig. 3, 5). The shallow positive buoyancy region found by the radiosonde leads to a much more negative vertically integrated buoyancy value compared to the nearest CopterSonde observation (Fig. 6).

The proposed buoyancy method is applied to both datasets, seen in Fig. 5. Unlike the CopterSonde derived heights using the potential temperature method (Fig. 5a), the buoyancy method provides more consistent, realistic heights. It is worth noting that some heights appear to surpass the provided data, this is a smoothing artifact from plotting. The 1724-2300 UTC time period has more agreement from profile to profile (Fig. 5a) as well as with the radiosonde derived heights (Fig. 5b). Furthermore, 
the radiosonde derived heights using the potential temperature method (Fig. 4b) and buoyancy method (Fig. 5b) are identical throughout the entire period. The correlation $(\mathrm{r}=1.0)$ between the buoyancy method and potential temperature method bolsters confidence that the buoyancy method is promising to determine ABL heights. Once the jet arrives and mechanically mixes the surface layer, there is a rise in ABL heights across all methods and datasets (Fig. 4, 5). Afterwards, the agreement between the potential temperature (Fig. 4a) and buoyancy (Fig. 5a) methods from CopterSonde data improves. As with most gradient methods, it suggests that the buoyancy method would perform better in convective boundary layers than stable boundary layers.

In a similar manner to the rise and fall of ABL height, Fig. 6 shows the change in vertically integrated buoyancy throughout time. Since buoyancy is dictated by temperature differences, diurnal changes in insolation give the graph a sinusoidal shape. This is shown by both platforms even though there is some variability. Peak vertically integrated buoyancy occurs at the same time as peak surface temperature (Fig. 2). Radiative cooling of the surface causes the integrated buoyancy to sharply decrease as the sun sets. Contrary to findings in Shapiro et al. (2016), the maximum buoyancy occurs a few hours before sunset. Upon the arrival of the LLJ, there is a rapid increase in buoyancy, as a result of rising temperature. Turbulent forces act to return the ABL to a neutral state, allowing the environment to quickly become positively buoyant once daytime heating begins.

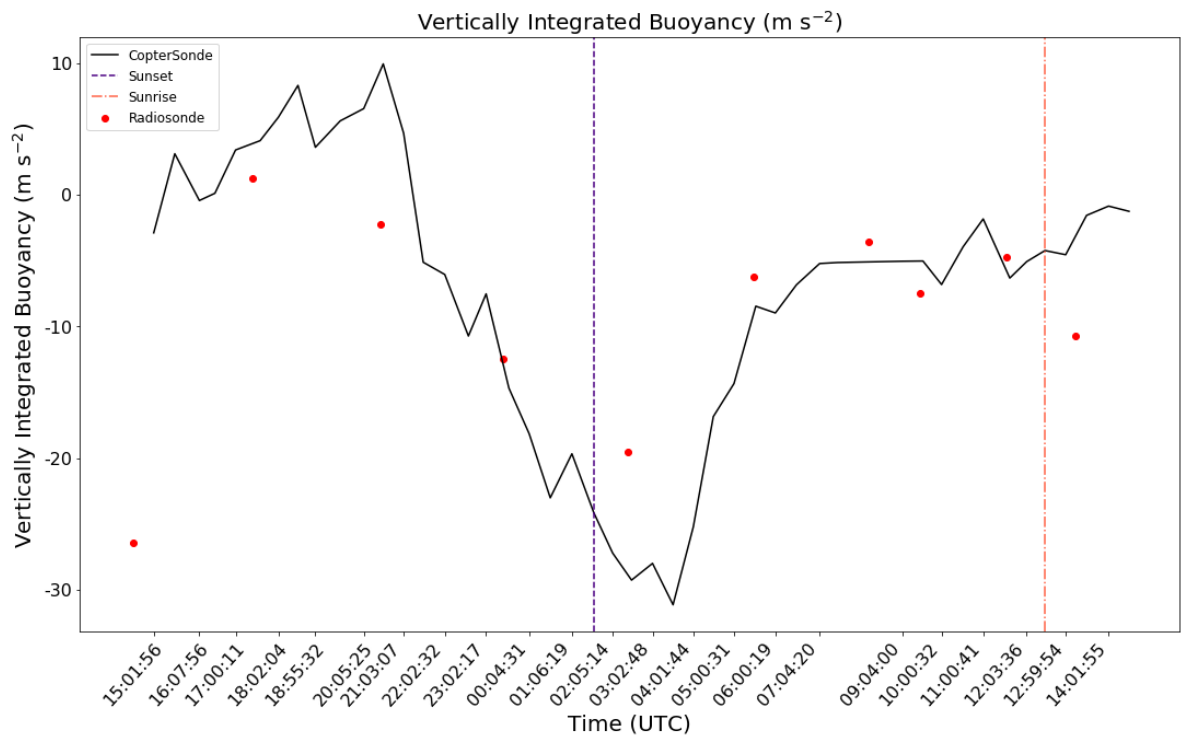

Figure 6. Time series of vertically integrated buoyancy $\left(\mathrm{m} \mathrm{s}^{-2}\right)$. Black line is CopterSonde data, red dots are radiosonde data. Purple and orange vertical lines represent sunset and sunrise, respectively.

\subsection{Case 2: LAPSE-RATE}

Before LAPSE-RATE began, forecast models specific to the valley were run to predict which days would be best suited for the different research objectives: CI, drainage flows, and boundary layer transitions. The first 2 days of the campaign (15-16 July 2018) were selected to study CI. Both days had moist environments with a rapidly destabilizing ABL. The weak ridge and lack of wind shear promoted isolated convection. This study will focus on 15 July 2018 since it experienced CI within 


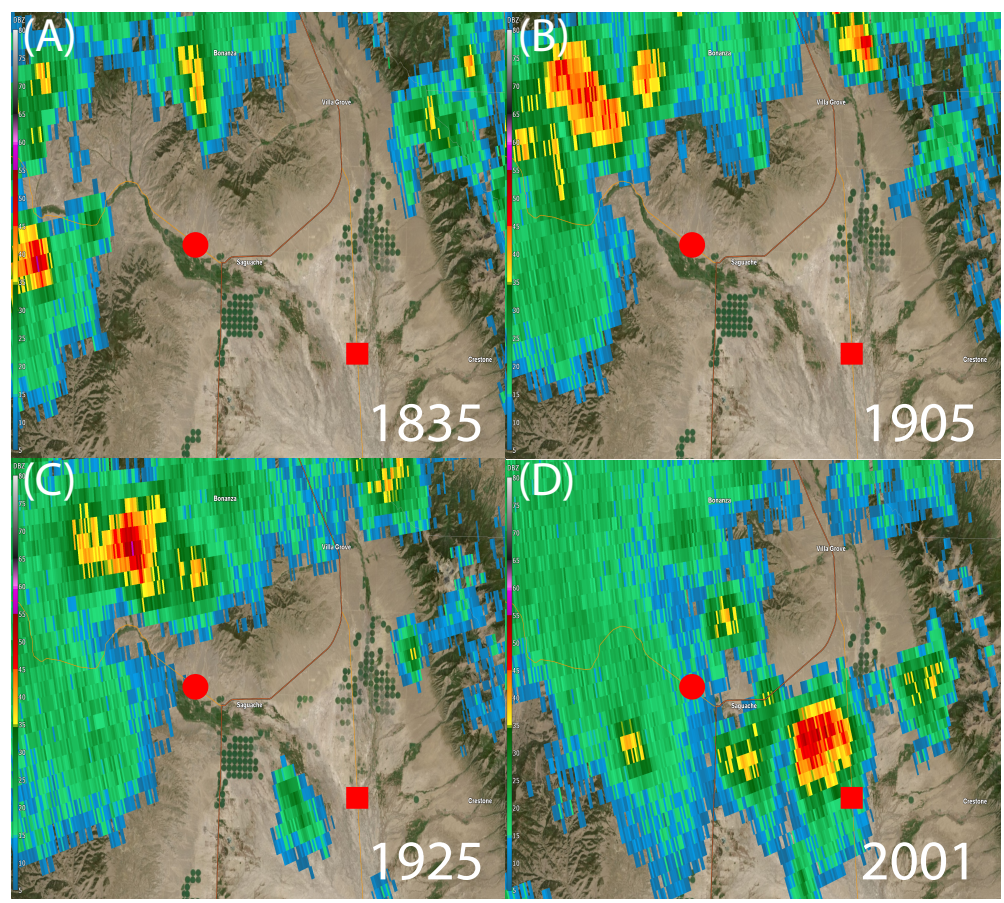

Figure 7. $0.5^{\circ}$ level reflectivity (dBZ) from the KPUX radar in Pueblo, CO over the SLV on 15 July 2018. Red circle indicates the K04V site and red square indicates MOFF. a) 1835 UTC (1235 MDT) b) 1905 UTC (1305 MDT) c) 1925 UTC (1325 MDT) d) 2001 UTC (1401 MDT).

the valley, including directly over K04V (Fig. 8a). Fortunately, convection initiated over a profiling site, thus providing local discrepancies in pre-convective variables.

At 1715 UTC, the automated surface observing system (ASOS) stationed at K04V reports distant lightning and archived radar shows convection $25 \mathrm{~km}$ north of the site. Two hours later, the same ASOS station reports a thunderstorm. As a result, flights at K04V end 30 min before flights at MOFF. At this time, archived radar shows the deepest convection is still $10 \mathrm{~km}$ north (Fig. 7). This highlights the issues of radar coverage within the valley. Storms are not seen by the radar unless they are taller than the mountains. Around 1955 UTC, CI occurs 4 km east of MOFF. At 2001 UTC, the site only receives light rain with stronger convection moving north. These times will become useful as we analyze the buoyancy and moisture fields.

Figure 8 shows how buoyancy and moisture evolve in time with height at both sites. In the morning, there is more moisture throughout the column at MOFF than K04V. The drier air near the surface heats more quickly and leads to faster destabilization at K04V. From 1700-1740 UTC there is a strong positive buoyancy gradient in time at K04V. Here, buoyancy is uniform throughout the entire layer. In addition, low-level moisture increases with time. It is possible this is a result of moisture convergence induced by outflow from the storms to the north. Rapid destabilization coupled with deepening low-level moisture creates a favorable convective environment. Consequently, the K04V ASOS reports $14 \mathrm{~m} \mathrm{~s}^{-1}$ gusts from 1954 - 2030 UTC. Conversely, at MOFF there is little change in buoyancy with time and moisture decreases with time (Fig. 8b). Once convection 

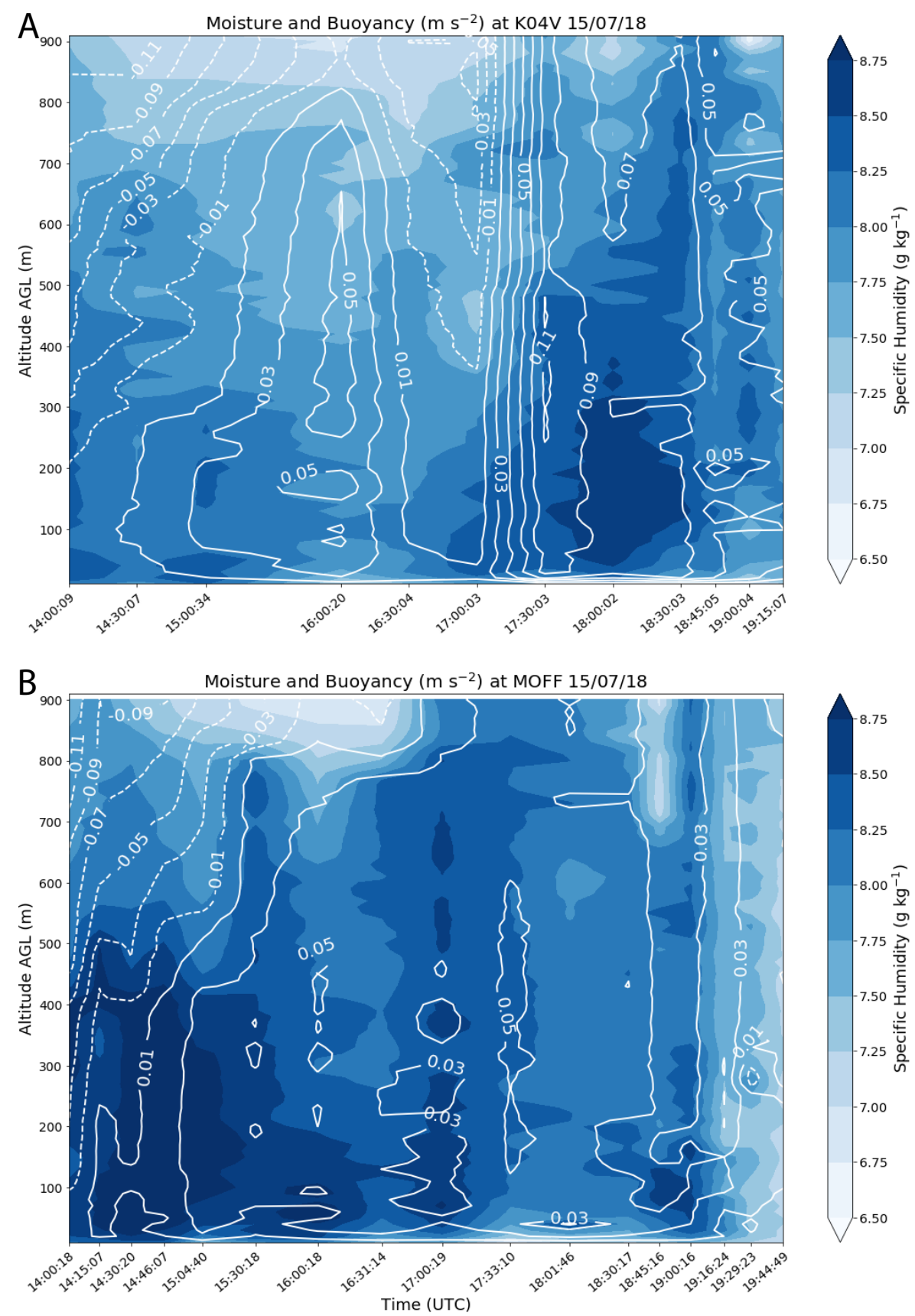

Figure 8. Buoyancy contours $\left(\mathrm{m} \mathrm{s}^{-2}\right.$ ) where solid(dashed) are positive(negative) and specific humidity ( $\mathrm{g} \mathrm{kg}^{-1}$ ) filled contours from CopterSondes on 15 July 2018 (CI day). (a) data from K04V. (b) data from MOFF. Each time shown on the x-axis represents the time of CopterSonde flight. 
begins in the valley (2000 UTC), MOFF is drier and neutrally buoyant. As a result, the storm favors northward propagation, away from MOFF.

Even though the two sites are only about $27 \mathrm{~km}$ apart, there is a difference in how buoyancy evolves in time, showing its spatial sensitivity. Variations in moisture over the two locations change the rate of surface heating. Differences in moisture could be attributed to different land cover or different positions within the valley. Surface observations influence parcel trajectory, and buoyancy infers deviations about the environmental profile. Increased representation of land-air interactions is a valuable asset to any forecasting tool. These microscale features are often smoothed over by other variables such as potential temperature because it is independent of surface conditions. Buoyancy in convective settings is sensitive to environmental changes, which may predate the amplification or weakening of convection.

In contrast, Fig. 9 shows the same variables but for a non-CI case that experienced cold air drainage. Buoyancy aloft is predominantly negative and has a strong gradient in time and height. Radiational cooling causes the air above the surface to become denser and descend the valley walls. The strong easterly winds throughout the early morning indicate strong downsloping flow (Fig. 10). The process continues throughout the night resulting in a cold pool of air at the base of the valley. Thus, a strong temperature inversion settles in with subsequent negative buoyancy. About an hour after sunrise (1148 UTC), the surface has warmed enough to dilute the density current, which causes the flow to stagnate within the lowest $100 \mathrm{~m}$ (Fig. 10). Figure 9 shows how deep the stable layer is until 1400 UTC. As the surface warms, a shallow mixed layer grows, but is still capped by a stable layer. This region is convectively neutral with increasing mixed layer depth (Fig. 9). Not until 1530 does the wind direction shift to southerly, generating some positive buoyancy (Fig. 9, 10). This boundary layer transition is unlike either of the other cases examined. Since cold air pools into a thick layer at the base of the valley, the magnitude of stability surpasses what would occur from radiational cooling over flat land. As a result, valley cold pools can lead to persistent fog (Chachere and $\mathrm{Pu}, 2016$ ). Understanding the timing of mechanical mixing and fog dissipation would aid aviation forecasts.

\section{Conclusions}

This study uses buoyancy measured from RPAS to describe transitions within the ABL. Two cases are evaluated to understand the versatility of using low-level buoyancy. Recent developments in weather sensing RPASs allow for high-frequency sampling within the ABL. The CopterSonde measures at a higher vertical resolution than radiosondes with comparable accuracy (Fig. 2, 6). Buoyancy has been used prevalently in model studies to interpret microscale to mesoscale processes. The spatial and temporal sensitivity of buoyancy allows for more interpretation of fine-scale processes. The results show that buoyancy has a diurnal cycle coinciding with the solar cycle (Fig. 6). Buoyancy becomes convectively mixed like potential temperature below the ABL, such that the maximum height of isotropic buoyancy appears to transition with the ABL depth (Fig. 3, 8).

The application of vertical buoyancy gradients to derive the ABL height shows promising initial results. The potential temperature and buoyancy method derived heights perfectly correlate $(r=1.0)$ when radiosonde data are used. The correlation from the two methods, using CopterSonde data is not as strong ( $\mathrm{r}=0.45)$. Although, the buoyancy method heights are comparable to the heights derived from the radiosonde data. These heights agree better across methodologies with the radiosonde data than the 


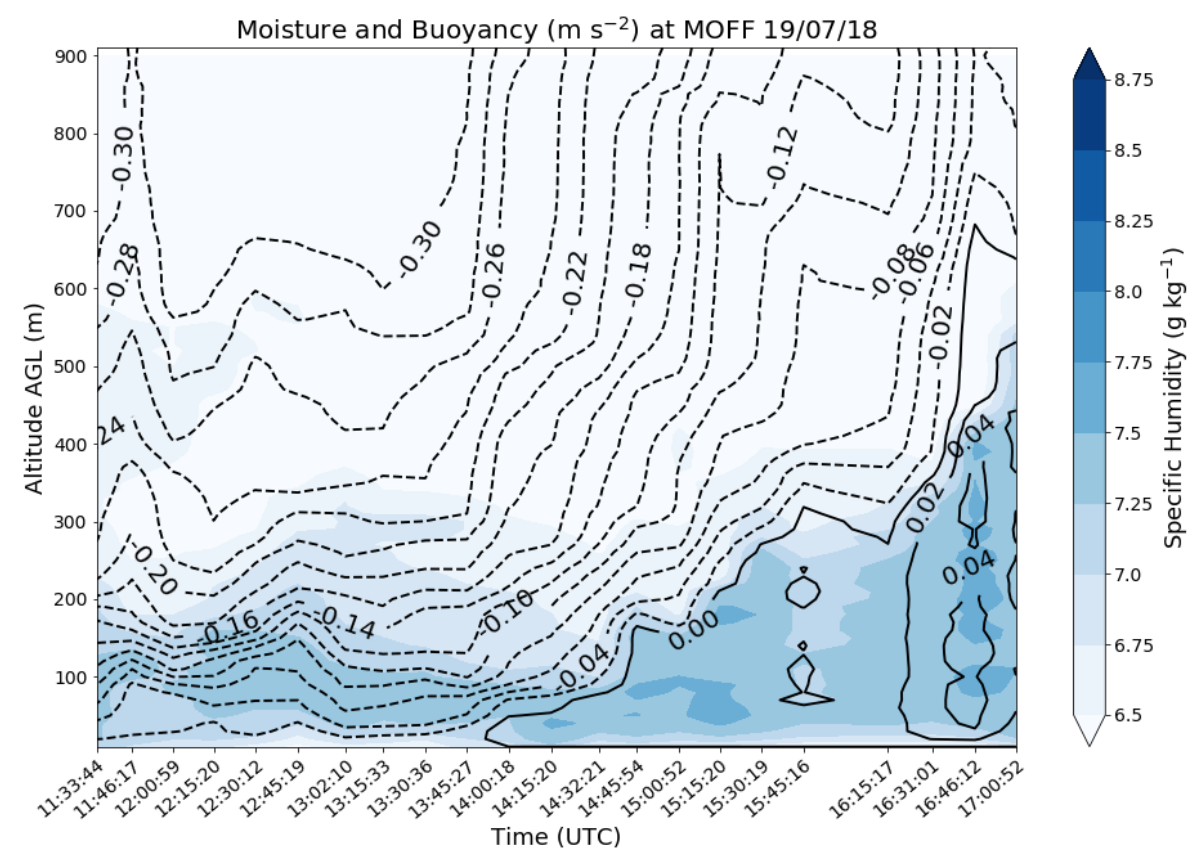

Figure 9. Buoyancy contours $\left(\mathrm{m} \mathrm{s}^{-2}\right.$ ) where solid(dashed) are positive(negative) and specific humidity ( $\mathrm{g} \mathrm{kg}^{-1}$ ) filled contours from CopterSondes on 19 July 2018 (drainage flow day) at MOFF.

potential temperature method with different data sources. Inherently, more cases need to be evaluated to have full confidence in the method. Moreover, there are avenues to improve the buoyancy method, particularly when using the CopterSonde data. The high vertical resolution leads to noise in the profiles that is erroneously picked up as the ABL height. Logical arguments will be applied to reduce inconsistencies in ABL heights for consecutive flights. Also, a technique to exclude heights that are beyond the flight ceiling is necessary. The success of this simple method gives credence that with proper improvements it could become a trusted ABL height definition.

The two cases show the versatility of buoyancy in different scenarios. While it is beyond the scope of this study to interpret the factors creating the buoyancy gradient, they agree with past findings. Figure 3 displays a negative buoyancy gradient beginning two hours before the jet arrives. It is expected that there is a stable boundary layer during nocturnal LLJ (Blackadar, 1957). Moreover, sinking air ahead of the jet would increase stability. As for case 2, Fig. 8a shows an acceleration in positive buoyancy leading up to CI. This agrees with Trier et al. (2014) that there is rapid destabilization before CI quantified by parcel buoyancy. MOFF has weaker buoyancy (Fig. 8b) and results in shallower convection than K04V. Further investigation is required to see if this is a common occurrence preceding other events.

Real time sampling allows for data assimilation and improvement in ABL representation for NWP. There is potential for buoyancy to evaluate many other microscale to mesoscale processes. Measurements taken along a dryline could increase understanding of where horizontal convective rolls (HCR) occur. HCR are conducive for CI due to vertical motion and ther- 


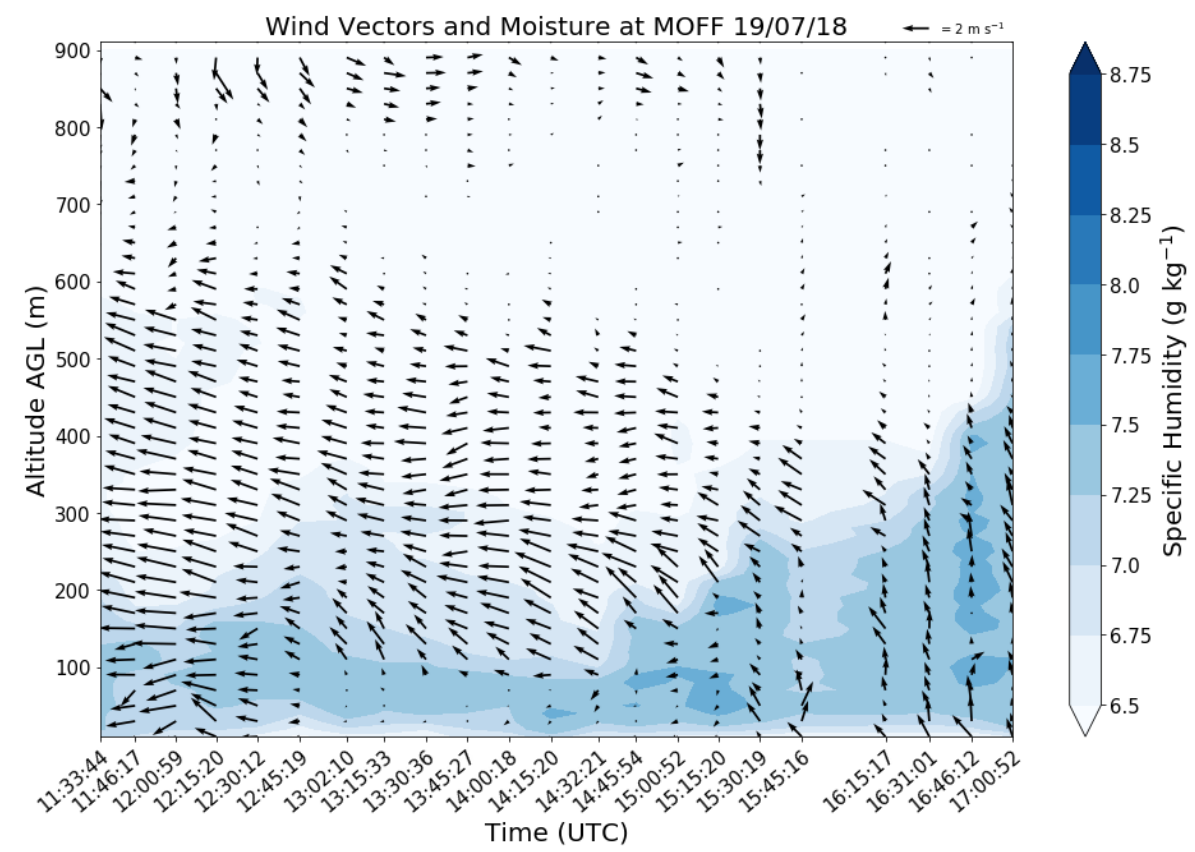

Figure 10. Wind vectors over specific humidity $\left(\mathrm{g} \mathrm{kg}^{-1}\right)$ filled contours from CopterSondes on 19 July 2018 (drainage flow day) at MOFF.

modynamic gradients described in Weckwerth et al. (1999). Furthermore, understanding cold pool strength and propagation would aid in forecasting severe weather like mesoscale convective systems. Additionally, RPASs can fill a gap in measurements in urban settings to increase understanding of turbulence and aerosol transport. Buoyant plumes transport aerosols throughout the city, but measuring this typically requires non-permanent towers and tracers, such as smoke or colored aerosols. RPASs deployed to determine buoyancy within the urban canopy could help improve air quality predictions. There are countless applications for RPASs to sample previously difficult aspects of the atmosphere.

Regular RPAS profiling opens avenues for increased data assimilation for climate, air quality, and NWP. Buoyancy is just one variable that has shown use in describing the state of the ABL, which was not previously accessible. Buoyancy is sensitive, physical, and simple. Furthermore, remote sensing platforms could use this technique. There are opportunities to improve the buoyancy calculation, such as using virtual temperature in the calculation; this will be considered in future studies. This study is a simple starting point to revive a classically defined variable in light of new technology. Buoyancy measured by RPASs can describe ABL transitions with little computational power while providing more information than traditional ABL variables. 
https://doi.org/10.5194/amt-2021-68

Preprint. Discussion started: 14 June 2021

(c) Author(s) 2021. CC BY 4.0 License.

(c) (i)

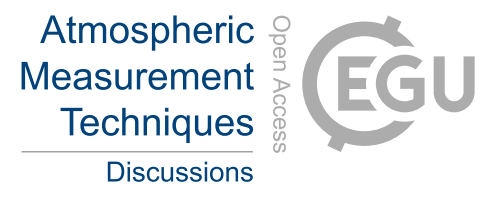

315 Author contributions. Data was collected by T.B., E.P.L and P.C.; Data processing and quality control were conducted by T.B.; Data analysis and visualization was performed by F.L.; The manuscript was written by F.L. with contributions from all co-authors

Competing interests. The authors declare that they have no conflicts of interest.

Acknowledgements. Funding is provided by the NASA University Leadership Initiative under Grant Number 80NSSC20M0162. This research has been supported in part by the National Science Foundation under Grant Number 1539070 and internal funding from the University of Oklahoma Office of the Vice President for Research and Partnerships. The authors would also like to thank the greater San Luis Valley community for welcoming the LAPSE-RATE campaign and providing land access for flight operations. Additionally, we thank those CASS members who gathered and processed the CopterSonde data for both campaigns. 


\section{References}

Ágústsson, H., Ólafsson, H., Jonassen, M. O., and Rögnvaldsson, ó.: The impact of assimilating data from a remotely piloted aircraft on simulations of weak-wind orographic flow, Tellus A: Dynamic Meteorology and Oceanography, 66, $25421,2014$.

Baklanov, A. A., Grisogono, B., Bornstein, R., Mahrt, L., Zilitinkevich, S. S., Taylor, P., Larsen, S. E., Rotach, M. W., and Fernando, H.: The nature, theory, and modeling of atmospheric planetary boundary layers, Bulletin of the American Meteorological Society, 92, 123-128, 2011.

Banta, R. M., Pichugina, Y. L., and Newsom, R. K.: Relationship between low-level jet properties and turbulence kinetic energy in the nocturnal stable boundary layer, Journal of the atmospheric sciences, 60, 2549-2555, 2003.

Barbieri, L., Kral, S., Bailey, S., Frazier, A., Jacob, J., Reuder, J., Brus, D., Chilson, P., Crick, C., Detweiler, C., et al.: Small unmanned aircraft systems (sUAS) in atmospheric science: Measurement intercomparison for LAPSE-RATE, Sensors, 2019.

Båserud, L., Reuder, J., Jonassen, M. O., Kral, S. T., Bakhoday Paskyabi, M., and Lothon, M.: Proof of concept for turbulence measurements with the RPAS SUMO during the BLLAST campaign, 2016.

Bell, T. M., Greene, B. R., Klein, P. M., Carney, M., and Chilson, P. B.: Confronting the boundary layer data gap: evaluating new and existing methodologies of probing the lower atmosphere, Atmospheric Measurement Techniques, 13, 3855-3872, 2020a.

Bell, T. M., Klein, P. M., Lundquist, J. K., and Waugh, S.: Remote sensing and radiosonde datasets collected in the San Luis Valley during the LAPSE-RATE campaign, Earth System Science Data Discussions, pp. 1-19, 2020b.

Blackadar, A. K.: Boundary layer wind maxima and their significance for the growth of nocturnal inversions, Bulletin of the American Meteorological Society, 38, 283-290, 1957.

Boer, G. d., Houston, A., Jacob, J., Chilson, P. B., Smith, S. W., Argrow, B., Lawrence, D., Elston, J., Brus, D., Kemppinen, O., et al.: Data Generated During the 2018 LAPSE-RATE Campaign: An Introduction and Overview, Earth System Science Data Discussions, pp. 1-15, 2020.

Bonin, T., Chilson, P., Zielke, B., and Fedorovich, E.: Observations of the early evening boundary-layer transition using a small unmanned aerial system, Boundary-layer meteorology, 146, 119-132, 2013.

Braun, S. A. and Tao, W.-K.: Sensitivity of high-resolution simulations of Hurricane Bob (1991) to planetary boundary layer parameterizations, Monthly Weather Review, 128, 3941-3961, 2000.

Chachere, C. N. and Pu, Z.: Connections between cold air pools and mountain valley fog events in Salt Lake City, Pure and Applied Geophysics, 173, 3187-3196, 2016.

Chilson, P. B., Bell, T. M., Brewster, K. A., Britto Hupsel de Azevedo, G., Carr, F. H., Carson, K., Doyle, W., Fiebrich, C. A., Greene, B. R., Grimsley, J. L., et al.: Moving towards a Network of Autonomous UAS Atmospheric Profiling Stations for Observations in the Earth's Lower Atmosphere: The 3D Mesonet Concept, Sensors, 19, 2720, 2019.

Cohen, A. E., Cavallo, S. M., Coniglio, M. C., and Brooks, H. E.: A review of planetary boundary layer parameterization schemes and their sensitivity in simulating southeastern US cold season severe weather environments, Weather and forecasting, 30, 591-612, 2015.

Coniglio, M. C., Romine, G. S., Turner, D. D., and Torn, R. D.: Impacts of targeted AERI and Doppler lidar wind retrievals on short-term forecasts of the initiation and early evolution of thunderstorms, Monthly Weather Review, 147, 1149-1170, 2019.

Cuchiara, G. C., Li, X., Carvalho, J., and Rappenglück, B.: Intercomparison of planetary boundary layer parameterization and its impacts on surface ozone concentration in the WRF/Chem model for a case study in Houston/Texas, Atmospheric Environment, 96, 175-185, 2014. 
Dai, C., Wang, Q., Kalogiros, J., Lenschow, D., Gao, Z., and Zhou, M.: Determining boundary-layer height from aircraft measurements, Boundary-layer meteorology, 152, 277-302, 2014.

Dang, R., Yang, Y., Hu, X.-M., Wang, Z., and Zhang, S.: A review of techniques for diagnosing the atmospheric boundary layer height (ABLH) using aerosol lidar data, Remote Sensing, 11, 1590, 2019.

de Boer, G., Diehl, C., Jacob, J., Houston, A., Smith, S. W., Chilson, P., Schmale III, D. G., Intrieri, J., Pinto, J., Elston, J., et al.: Development of Community, Capabilities, and Understanding through Unmanned Aircraft-Based Atmospheric Research: The LAPSE-RATE Campaign, Bulletin of the American Meteorological Society, 101, E684-E699, 2020.

De Wekker, S. F., Ameen, A., Song, G., Stephens, B. B., Hallar, A. G., and McCUBBIN, I. B.: A preliminary investigation of boundary layer effects on daytime atmospheric CO 2 concentrations at a mountaintop location in the Rocky Mountains, Acta Geophysica, 57, 904-922, 2009.

Degelia, S. K., Wang, X., Stensrud, D. J., and Johnson, A.: Understanding the impact of radar and in situ observations on the prediction of a nocturnal convection initiation event on 25 June 2013 using an ensemble-based multiscale data assimilation system, Monthly Weather Review, 146, 1837-1859, 2018.

Dias, N., Gonçalves, J., Freire, L., Hasegawa, T., and Malheiros, A.: Obtaining potential virtual temperature profiles, entrainment fluxes, and spectra from mini unmanned aerial vehicle data, Boundary-layer meteorology, 145, 93-111, 2012.

Elston, J., Argrow, B., Stachura, M., Weibel, D., Lawrence, D., and Pope, D.: Overview of small fixed-wing unmanned aircraft for meteorological sampling, Journal of Atmospheric and Oceanic Technology, 32, 97-115, 2015.

Flagg, D. D., Doyle, J. D., Holt, T. R., Tyndall, D. P., Amerault, C. M., Geiszler, D., Haack, T., Moskaitis, J. R., Nachamkin, J., and Eleuterio, D. P.: On the Impact of Unmanned Aerial System Observations on Numerical Weather Prediction in the Coastal Zone, Monthly Weather Review, 146, 599-622, 2018.

Gebauer, J. G., Fedorovich, E., and Shapiro, A.: A 1D theoretical analysis of northerly low-level jets over the Great Plains, Journal of the Atmospheric Sciences, 74, 3419-3431, 2017.

Greene, B. R., Segales, A. R., Waugh, S., Duthoit, S., and Chilson, P. B.: Considerations for temperature sensor placement on rotary-wing unmanned aircraft systems, Atmospheric Measurement Techniques, 11, 5519, 2018.

Greene, B. R., Segales, A. R., Bell, T. M., Pillar-Little, E. A., and Chilson, P. B.: Environmental and sensor integration influences on temperature measurements by rotary-wing unmanned aircraft systems, Sensors, 19, 1470, 2019.

Hennemuth, B. and Lammert, A.: Determination of the atmospheric boundary layer height from radiosonde and lidar backscatter, BoundaryLayer Meteorology, 120, 181-200, 2006.

Houston, A. L. and Niyogi, D.: The sensitivity of convective initiation to the lapse rate of the active cloud-bearing layer, Monthly Weather Review, 135, 3013-3032, 2007.

Hu, J., Yussouf, N., Turner, D. D., Jones, T. A., and Wang, X.: Impact of ground-based remote sensing boundary layer observations on short-term probabilistic forecasts of a tornadic supercell event, Weather and Forecasting, 34, 1453-1476, 2019.

$\mathrm{Hu}$, X.-M., Nielsen-Gammon, J. W., and Zhang, F.: Evaluation of three planetary boundary layer schemes in the WRF model, Journal of Applied Meteorology and Climatology, 49, 1831-1844, 2010.

Jonassen, M. O., Ólafsson, H., Ágústsson, H., Rögnvaldsson, Ó., and Reuder, J.: Improving high-resolution numerical weather simulations by assimilating data from an unmanned aerial system, Monthly Weather Review, 140, 3734-3756, 2012.

395 Jones, T. A. and Stensrud, D. J.: Assimilating AIRS temperature and mixing ratio profiles using an ensemble Kalman filter approach for convective-scale forecasts, Weather and forecasting, 27, 541-564, 2012. 
Jones, T. A., Knopfmeier, K., Wheatley, D., Creager, G., Minnis, P., and Palikonda, R.: Storm-scale data assimilation and ensemble forecasting with the NSSL experimental Warn-on-Forecast system. Part II: Combined radar and satellite data experiments, Weather and Forecasting, 31, 297-327, 2016.

Koch, S. E., Fengler, M., Chilson, P. B., Elmore, K. L., Argrow, B., Andra Jr, D. L., and Lindley, T.: On the use of unmanned aircraft for sampling mesoscale phenomena in the preconvective boundary layer, Journal of Atmospheric and Oceanic Technology, 35, 2265-2288, 2018.

Kral, S. T., Reuder, J., Vihma, T., Suomi, I., O’Connor, E., Kouznetsov, R., Wrenger, B., Rautenberg, A., Urbancic, G., Jonassen, M. O., et al.: Innovative strategies for observations in the arctic atmospheric boundary layer (ISOBAR) - the Hailuoto 2017 campaign, Atmosphere, 9 , $268,2018$.

Lapworth, A.: The morning transition of the nocturnal boundary layer, Boundary-layer meteorology, 119, 501-526, 2006.

Lenschow, D., Stankov, B., and Mahrt, L.: The rapid morning boundary-layer transition, Journal of the atmospheric sciences, 36, 2108-2124, 1979.

Lewis, W. E., Wagner, T. J., Otkin, J. A., and Jones, T. A.: Impact of AERI Temperature and Moisture Retrievals on the Simulation of a Central Plains Severe Convective Weather Event, Atmosphere, 11, 729, 2020.

Martucci, G., Matthey, R., Mitev, V., and Richner, H.: Comparison between backscatter lidar and radiosonde measurements of the diurnal and nocturnal stratification in the lower troposphere, Journal of Atmospheric and Oceanic Technology, 24, 1231-1244, 2007.

National Research Council: Observing weather and climate from the ground up: A nationwide network of networks, National Academies Press, 2009.

415 Nilsson, E., Rannik, Ü., Kumala, M., Buzorius, G., and O’dowd, C.: Effects of continental boundary layer evolution, convection, turbulence and entrainment, on aerosol formation, Tellus B: Chemical and Physical Meteorology, 53, 441-461, 2001.

Nolan, D. S., Zhang, J. A., and Stern, D. P.: DP Stern, and JA Zhang, 2009b: Evaluation of planetary boundary layer parameterizations in tropical cyclones by comparison of in situ observations and high-resolution simulations of Hurricane Isabel (2003). Part II: Inner-core boundary layer and eyewall structure, Mon. Wea. Rev, 137, 3675-3698, 2009.

Otkin, J. A., Hartung, D. C., Turner, D. D., Petersen, R. A., Feltz, W. F., and Janzon, E.: Assimilation of surface-based boundary layer profiler observations during a cool-season weather event using an observing system simulation experiment. Part I: Analysis impact, Monthly Weather Review, 139, 2309-2326, 2011.

Pal, S., Lee, T., Phelps, S., and De Wekker, S.: Impact of atmospheric boundary layer depth variability and wind reversal on the diurnal variability of aerosol concentration at a valley site, Science of the Total Environment, 496, 424-434, 2014.

Pillar-Little, E. A., Greene, B. R., Lappin, F. M., Bell, T. M., Segales, A. R., de Azevedo, G. B. H., Doyle, W., Kanneganti, S. T., Tripp, D. D., and Chilson, P. B.: Observations of the thermodynamic and kinematic state of the atmospheric boundary layer over the San Luis Valley, CO using remotely piloted aircraft systems during the LAPSE-RATE field campaign, Earth System Science Data Discussions, pp. $1-17,2020$.

Reen, B. P., Stauffer, D. R., and Davis, K. J.: Land-surface heterogeneity effects in the planetary boundary layer, Boundary-layer meteorology, 150, 1-31, 2014.

Reuder, J., Brisset, P., Jonassen, M., Müller, M., and Mayer, S.: The Small Unmanned Meteorological Observer SUMO: A new tool for atmospheric boundary layer research, Meteorologische Zeitschrift, 18, 141-147, 2009.

Ruggiero, F. H., Sashegyi, K. D., Madala, R. V., and Raman, S.: The use of surface observations in four-dimensional data assimilation using a mesoscale model, Monthly weather review, 124, 1018-1033, 1996. 

the development of a smart unmanned aircraft system for atmospheric boundary layer research., Atmospheric Measurement Techniques, 13, 2020.

Seibert, P., Beyrich, F., Gryning, S.-E., Joffre, S., Rasmussen, A., and Tercier, P.: Review and intercomparison of operational methods for the determination of the mixing height, Atmospheric environment, 34, 1001-1027, 2000.

Shapiro, A. and Fedorovich, E.: Nocturnal low-level jet over a shallow slope, Acta Geophysica, 57, 950-980, 2009.

Shapiro, A., Fedorovich, E., and Rahimi, S.: A unified theory for the Great Plains nocturnal low-level jet, Journal of the Atmospheric Sciences, 73, 3037-3057, 2016.

Steeneveld, G., Mauritsen, T., De Bruijn, E., Vilà-Guerau de Arellano, J., Svensson, G., and Holtslag, A.: Evaluation of limited-area models for the representation of the diurnal cycle and contrasting nights in CASES-99, Journal of Applied Meteorology and Climatology, 47, 869-887, 2008.

Stull, R.: 1988: An Introduction to Boundary Layer Meteorology, K luwer A cademic Publishers, 1988.

Teixeira, J., Stevens, B., Bretherton, C., Cederwall, R., Doyle, J. D., Golaz, J.-C., Holtslag, A. A., Klein, S., Lundquist, J. K., Randall, D. A., et al.: Parameterization of the atmospheric boundary layer: a view from just above the inversion, Bulletin of the American Meteorological Society, 89, 453-458, 2008.

Trier, S. B., Davis, C. A., Ahijevych, D. A., and Manning, K. W.: Use of the parcel buoyancy minimum (B min) to diagnose simulated thermodynamic destabilization. Part I: Methodology and case studies of MCS initiation environments, Monthly Weather Review, 142, 945-966, 2014.

Villa, T. F., Gonzalez, F., Miljievic, B., Ristovski, Z. D., and Morawska, L.: An overview of small unmanned aerial vehicles for air quality measurements: Present applications and future prospectives, Sensors, 16, 1072, 2016.

455 Wagner, T. J., Klein, P. M., and Turner, D. D.: A new generation of ground-based mobile platforms for active and passive profiling of the boundary layer, Bulletin of the American Meteorological Society, 100, 137-153, 2019.

Weckwerth, T. M., Horst, T. W., and Wilson, J. W.: An observational study of the evolution of horizontal convective rolls, Monthly weather review, 127, 2160-2179, 1999.

Weisman, M. L. and Rotunno, R.: “A theory for strong long-lived squall lines” revisited, Journal of the Atmospheric Sciences, 61, 361-382, 2004.

Zhang, Y. and Klein, S. A.: Mechanisms affecting the transition from shallow to deep convection over land: Inferences from observations of the diurnal cycle collected at the ARM Southern Great Plains site, Journal of the Atmospheric Sciences, 67, 2943-2959, 2010.

Ziegler, C. L. and Rasmussen, E. N.: The initiation of moist convection at the dryline: forecasting issues from acase study perspective, Weather and forecasting, 13, 1106-1131, 1998. 